\title{
UTILIZAÇÃO DA OCITOCINA EM GADO GIROLANDO: AVALIAÇÃO DA VIA VAGINAL COMO ALTERNATIVA À VIA ENDOVENOSA
}

\section{USE OF OXYTOCIN IN GIROLANDO CATTLE: EVALUATION OF THE VAGINAL ROUT AS AN ALTERNATIVE TO INTRAVENOUS ROUT}

\author{
Cristina Loureiro Müller Pessôa Netto ${ }^{1^{*}}$ ORCID - http://orcid.org/0000-0003-4692-2038 \\ Helton Mattana Saturnino ${ }^{1}$ ORCID - http://orcid.org/0000-0001-5711-3493 \\ Paulo Ricardo de Oliveira Paes ${ }^{1}$ ORCID - http://orcid.org/0000-0002-1366-7352 \\ Igor Dimitri Gama Duarte ${ }^{1}$ ORCID - http://orcid.org/0000-0003-3891-5225 \\ Kelly Moura Keller ${ }^{1}$ ORCID - http://orcid.org/0000-0003-2882-512X \\ Fernando Antonio Bretas Viana1 ORCID - http://orcid.org/0000-0002-6943-4531
}

${ }^{1}$ Universidade Federal de Minas Gerais, Belo Horizonte, MG, Brasil.

*Autora para correspondência - cristinavet@zootec.mest.ufmg.br

\section{Resumo}

O objetivo deste trabalho foi testar a viabilidade da utilização da via vaginal em fêmeas bovinas visando à aplicação de ocitocina a partir de formulações específicas. A ocitocina foi utilizada associada a facilitadores de absorção e na forma injetável (para comparação). Foram produzidas sete formulações, todas com concentração de $5 \mathrm{UI} / \mathrm{mL}$ de ocitocina. O delineamento experimental foi em quadrado latino $8 \times 8$ (oito dias, oito tratamentos e oito novilhas ciclando). As administrações de ocitocina foram pela via vaginal e a ocitocina injetável pela via endovenosa, contendo 10 UI cada. Amostras de sangue $(n=7)$ foram coletadas de cada animal, no tempo 0, anterior à administração dos tratamentos, e de três em três minutos até 18 minutos. A ocitocina foi extraída do plasma utilizando coluna cromatográfica C-18 e dosada utilizando o kit comercial Oxytocin EIA. Os resultados obtidos foram avaliados por análise estatística não paramétrica utilizando o teste Kruskal Wallis para comparação das médias. A concentração de ocitocina diferiu entre o tempo 0 e o tempo 12 minutos $(\mathrm{p}<0,05)$ para a formulação ocitocina em glicerina. Concluiu-se que houve absorção através da via vaginal para essa formulação. Mais estudos serão necessários para seu emprego no manejo com as fêmeas bovinas de forma efetiva.

Palavras-chave: vacas, produção de leite, ordenha, ejeção do leite

\begin{abstract}
The aim of this study was to test the feasibility of vaginal route in order to apply oxytocin in female bovines using specific formulations. The oxytocin was used in its injectable form (as a comparison standard) and associated with absorption enhancers. Seven formulations containing $5 \mathrm{IU} / \mathrm{ml}$ of oxytocin each were used. The experimental design was an $8 \times 8$ latin square (eight days, eight treatments and eight cycling heifers). The formulations were delivered in vaginal route and the injectable oxytocin was applied intravenously, all of them having $10 \mathrm{IU}$ of oxytocin. Blood samples $(n=7)$ were collected from each animal, the first at time 0 , prior to the administration of
\end{abstract}


the treatment, and the following every three minutes until 18 minutes. Oxytocin was extracted from plasma using the C18 Sep-Pak column and measured with the commercial kit Oxytocin EIA. The responses were evaluated using the nonparametric ANOVA and the Kruskal Wallis test was used to compare the means. Statistical difference was observed between times 0 and $12(p<0,05)$ for the oxytocin plus glycerin formulation, showing that absorption did occur. Nonetheless, it does not suppress the need for further research before it can be effectively used in female bovine management.

Key-words: cows, milk yield, milking, milk ejection

Recebido em: 18 de maio de 2017

Aceito em 17 de outubro de 2018

\section{Introdução}

Um dos principais entraves à exploração intensiva na produção de leite do gado mestiço no Brasil (principalmente animais $\mathrm{F} 1$, taurino $\mathrm{x}$ zebuíno), relatado por técnicos e produtores, está relacionado à ordenha.

Após estímulos sensoriais, auditivos, táteis, olfatórios e/ou visuais, impulsos nervosos aferentes desencadeados pelos receptores sensíveis à pressão da pele e do teto percorrem a medula espinal até os núcleos supraóptico e paraventricular no hipotálamo, promovendo um estímulo sincronizado intermitente ${ }^{(1)}$. Assim, do hipotálamo, o estímulo segue via neurônios ocitocinérgicos até a neurohipófise. $O$ influxo de cálcio promove a fusão dos grânulos e a exocitose dos conteúdos granulares, promovendo a liberação pulsátil da ocitocina no leito capilar. Em aproximadamente 20 segundos, esta atua na glândula mamária, promovendo a ejeção do leite $^{(2,3)}$ -

Enquanto o leite é drenado da cisterna pela ordenha, o espaço criado vai sendo preenchido pelo leite alveolar. Para obter a remoção completa do leite alveolar, é necessário que a ocitocina seja liberada durante todo o tempo de ordenha ${ }^{(4)}$. Quando a ordenha é incompleta, parte do leite permanece dentro do alvéolo após seu término, constituindo o leite residual. Os distúrbios de ejeção do leite podem aumentar o volume de leite residual acima do aceitável, interferindo negativamente na lactação ${ }^{(5)}$.

A prática de ordenhar vacas mestiças com bezerro ao pé era adotada por mais de $80 \%$ dos produtores entrevistados em pesquisa realizada em Minas Gerais, embora as orientações técnicas fossem voltadas para o aleitamento artificial $^{(6)}$. Isto se justificava porque a ordenha manual e/ou a amamentação na sala de ordenha resultava na liberação contínua da ocitocina na corrente sanguínea pela neurohipófise ${ }^{(7)}$.

A inibição da ejeção do leite por ação central, quando não há suficiente liberação de ocitocina, tem sido observada em vacas ordenhadas em ambiente desconhecido ${ }^{(8,9)}$, em primíparas logo após o parto ${ }^{(8,10)}$, em vacas no cio $^{(8)}$ e em vacas Girolando F1 ordenhadas sem a presença da cria ${ }^{(11)}$. Quando isto ocorre, a administração de dose fisiológica de ocitocina pode restabelecer a ejeção do leite ${ }^{(8)}$.

No entanto, a utilização de ocitocina injetável para estimular a ejeção de leite na rotina de ordenha 
pode trazer problemas como a disseminação de doenças (Trypanossomose bovina, leucose, entre outras), o que ocorreu, por exemplo, em seis municípios de Minas Gerais em julho de 2014, quando um surto de Trypanossomose levou à morte muitas vacas e causou grande prejuízo para os produtores $^{(12)}$.

Em um levantamento dos impactos econômicos causado por trypanossoma vivax em rebanho bovino leiteiro, foram verificados mortes diretas, abortos, natimortos, redução no ganho de peso e na produção de leite, além dos gastos com drogas tripanocidas ${ }^{(13)}$.

O objetivo deste trabalho foi testar uma forma alternativa de administração da ocitocina - a via vaginal - diversa da prática usual - de aplicação endovenosa - para reduzir o risco da disseminação de doenças. Essa via tem sido explorada para a aplicação de fármacos de ação sistêmica por sua grande área de superfície, alta vascularização e permeabilidade a uma vasta gama de compostos, incluindo os de grande peso molecular como peptídeos e proteínas ${ }^{(14,15)}$.

\section{Materiais e Métodos}

Este trabalho foi aprovado pela Comissão de Ética no Uso de Animais (CEUA) da UFMG, sob o protocolo 116/2013. Foram produzidas sete formulações com ocitocina para aplicação vaginal: Ocitocina em Água, Ocitocina em Álcool Polivinílico (PVA) 4\% P/V, Ocitocina em Carboxi Metil Celulose (CMC) 2\% P/V, Ocitocina em Glicerina 2\% V/V, Ocitocina em Dimetilsulfóxido (DMSO) 10\% V/V, Ocitocina em Propilenoglicol 25\% V/V, Ocitocina em Tween 80 10\% V/V, todas com concentração de $5 \mathrm{UI} / \mathrm{mL}$. Os produtos associados foram selecionados por serem agentes facilitadores de absorção, com o objetivo de verificar suas habilidades de favorecer a absorção de ocitocina, visando atingir maior concentração plasmática no menor tempo possível. A ocitocina injetável usada foi uma formulação comercial (Placentex - União Química Farmacêutica Nacional S A.).

O experimento foi realizado na Fazenda Experimental Hélio Barbosa, da UFMG, localizada no município de Igarapé, MG. A duração do período de coleta foi de oito dias, de $1^{\circ}$ a 8 de outubro de 2015. Oito novilhas $3 / 4$ Girolando ciclando, com idades entre 15 e 28 meses e pesos entre 310 e $410 \mathrm{~kg}$, foram submetidas aos tratamentos. Nenhuma ação de interferência ou identificação da fase em que se encontravam no ciclo estral foi realizada, não foram inseminadas e/ou cobertas.

O experimento consistiu na aplicação endovaginal de $2 \mathrm{~mL}$ (10 UI) das sete formulações de ocitocina e uma aplicação endovenosa de $1 \mathrm{~mL}$ (10 UI) de ocitocina comercial, totalizando 8 tratamentos por dia. Ao longo de oito dias, todos os animais foram submetidos a uma aplicação de cada um dos tratamentos. O delineamento experimental foi em quadrado latino 8x8 (oito dias, oito tratamentos e oito novilhas - Quadro 1). 
Quadro 1. Modelagem de delineamento em QL 8x8 de novilhas Girolando submetidas a oito formulações contendo ocitocina sintética

\begin{tabular}{|c|cccccccc|}
\hline \multirow{2}{*}{$\begin{array}{c}\text { Animais } \\
\text { (linhas) }\end{array}$} & \multicolumn{7}{|c|}{ Dias (colunas) } \\
\cline { 2 - 9 } & $\mathbf{1}$ & $\mathbf{2}$ & $\mathbf{3}$ & $\mathbf{4}$ & $\mathbf{5}$ & $\mathbf{6}$ & $\mathbf{7}$ & $\mathbf{8}$ \\
\hline 1 & A & D & G & H & E & F & C & B \\
2 & D & A & F & E & H & G & B & C \\
3 & G & F & A & B & C & D & E & H \\
4 & B & C & H & G & F & E & D & A \\
5 & C & B & E & F & G & H & A & D \\
6 & F & G & D & C & B & A & H & E \\
7 & E & H & C & D & A & B & G & F \\
8 & H & E & B & A & D & C & F & G \\
\hline
\end{tabular}

Notas: (A) Ocitocina em Água; (B) Ocitocina em PVA; (C) Ocitocina em CMC; (D) Ocitocina em Glicerina; (E) Ocitocina comercial injetável; (F) Ocitocina em DMSO; (G) Ocitocina em Propilenoglicol, e (H) Ocitocina em Tween80.

A formulação contendo ocitocina foi introduzida na via vaginal utilizando uma sonda uretral $\mathrm{n}^{\mathrm{o}}$ 8 , de uso individual, acoplada a uma seringa. A ocitocina endovenosa foi aplicada na veia jugular.

As amostras de sangue foram colhidas da veia jugular usando seringa de $10 \mathrm{~mL}$, no momento anterior à aplicação da ocitocina (tempo zero) e por mais seis vezes a cada 3 minutos, e foram colocadas em tubos heparinizados, os quais foram acondicionados em caixa térmica com gelo e centrifugadas a $3.000 \mathrm{G}$ por 15 minutos para obtenção de plasma. Em seguida, estes foram transferidos para tubos epeendorfs e armazenados inicialmente a $-20^{\circ} \mathrm{C}$ e depois a $-70^{\circ} \mathrm{C}$.

A ocitocina foi extraída do plasma utilizando coluna cromatográfica C-18 produzida pela empresa Waters (Waters Technologies do Brazil LTDA, Al. Tocantins, $125 / 27^{\circ}$ andar Alphaville Barueri/SP) e dosada utilizando o kit Elisa comercial da Enzo (Enzo Life Sciences (ELS) AG, Industriestrasse 17 CH-4415 Lausen - Switzerland) (Oxytocin EIA).

Os dados foram analisados utilizando o programa estatístico InfoState, versão 2012. Foi realizada a análise de variância não paramétrica, utilizando o teste Kruskal Wallis para comparação das médias.

\section{Resultados}

Os valores na tabela abaixo demonstram as concentrações medianas de ocitocina obtida ao longo do tempo após aplicação das oito formulações de ocitocina. 
Tabela 1. Concentrações de ocitocina em novilhas Girolando (mediana, $\mathrm{pg} / \mathrm{mL}$ ), ao longo do tempo, valores mínimos, máximos e número de repetições

\begin{tabular}{|c|c|c|c|c|c|c|c|}
\hline \multirow[b]{2}{*}{ Tratamento } & \multicolumn{7}{|c|}{ Tempo em minutos } \\
\hline & 0 & 3 & 6 & 9 & 12 & 15 & 18 \\
\hline $\begin{array}{l}\text { Ocitoc ina com } \\
\text { Agua }\end{array}$ & $\begin{array}{c}17,25^{1 . A B} \\
(11,72-27,76) \\
n=7\end{array}$ & $\begin{array}{c}20,98^{24 B C} \\
(10,90-30,75) \\
n=8\end{array}$ & $\begin{array}{c}18,32^{\text {aABC }} \\
(7,51-47,54) \\
n=8\end{array}$ & $\begin{array}{c}18,04^{3 . A B} \\
(6,42-35,15) \\
n=8\end{array}$ & $\begin{array}{c}22,95^{-A B C D} \\
(11,48-62,47) \\
n=8\end{array}$ & $\begin{array}{c}18,84^{2+18} \\
(7,51-37,04) \\
n=8\end{array}$ & $\begin{array}{c}17,13^{2 . A B} \\
(7,32-31,66) \\
n=8\end{array}$ \\
\hline $\begin{array}{l}\text { Ocitoc ina com } \\
\text { Álcool } \\
\text { Polivinilico }\end{array}$ & $\begin{array}{c}\mathbf{2 0 , 7 7}=A B C \\
(5,73-40,84) \\
n=5\end{array}$ & $\begin{array}{c}24,44 . A B C \\
(6,24-34,51) \\
n=8\end{array}$ & $\begin{array}{c}15,41^{* A B} \\
(11,25-37,36) \\
n=8\end{array}$ & $\begin{array}{c}15,27^{=A B} \\
(8,08-28,17) \\
n=8\end{array}$ & $\begin{array}{c}13,86^{\text {AB }} \\
(9,50-24, \infty) \\
\mathrm{n}=8\end{array}$ & $\begin{array}{c}16,43^{2 A B} \\
(3,31-39,72) \\
n=8\end{array}$ & $\begin{array}{c}19,21^{\wedge A B} \\
(4,16-33,00) \\
n=8\end{array}$ \\
\hline $\begin{array}{l}\text { Ocitoc ina com } \\
\text { CMC }\end{array}$ & $\begin{array}{c}16,26^{3 A B} \\
(10,80-20,71) \\
n=8\end{array}$ & $\begin{array}{c}15,60 \text { s.AB } \\
(6,07-28,58) \\
n=8 \\
\end{array}$ & $\begin{array}{c}16,54^{3 . A B} \\
(6,95-33,53) \\
n=8\end{array}$ & $\begin{array}{c}13,56^{1 A B} \\
(7,89-38,63) \\
n=8 \\
\end{array}$ & $\begin{array}{c}15,67^{3 A B} \\
(5,73-24,23) \\
n=8 \\
\end{array}$ & $\begin{array}{c}14,11^{2.4 B} \\
(8,08-2498) \\
n=S\end{array}$ & $\begin{array}{c}17,25^{a A B} \\
(5,24-31,20) \\
n=7\end{array}$ \\
\hline $\begin{array}{l}\text { Ocitoc ina com } \\
\text { Glice rina }\end{array}$ & $\begin{array}{c}15,54^{1, A B} \\
(9,71-27,34) \\
n=8\end{array}$ & $\begin{array}{c}20,38^{a b A B} \\
(4,46-22,07) \\
n=8\end{array}$ & $\begin{array}{c}15,25 \\
(7,51-27,76 \\
n=8 \\
\end{array}$ & $\begin{array}{c}16,25^{\text {abds }} \\
(10,58-32,12) \\
n=8\end{array}$ & $\begin{array}{c}23,51 \text { bBCDE } \\
(12,20-34,01) \\
n=8\end{array}$ & $\begin{array}{c}15,75^{2,18} \\
(7,14-31,66) \\
n=8\end{array}$ & $\begin{array}{c}23,10 \text { sb } A B C \\
(10,36-30,75) \\
n=8\end{array}$ \\
\hline $\begin{array}{l}\text { Ocitocina } \\
\text { endovenosa }\end{array}$ & $\begin{array}{c}18,77^{* A B} \\
(12,44-27,34) \\
n=8\end{array}$ & $\begin{array}{c}146,66^{d P} \\
(119,34-216,90) \\
n=8\end{array}$ & $\begin{array}{c}82,86^{c A F} \\
(47,34-130,59) \\
n=8\end{array}$ & $\begin{array}{c}71,15^{\mathrm{bcF}} \\
(38,09-115,92) \\
n=8\end{array}$ & $\begin{array}{c}47,16^{\text {bcF }} \\
(27,34-103,14) \\
n=8\end{array}$ & $\begin{array}{c}36,55 \text { abCDEF } \\
(14,20-76,79) \\
n=8\end{array}$ & $\begin{array}{c}36,12 \text {; } \mathrm{bDFF} \\
(23,49-78,90) \\
n=8\end{array}$ \\
\hline $\begin{array}{l}\text { Ocitoc ina com } \\
\text { DMSO }\end{array}$ & $\begin{array}{c}16,58^{A A B} \\
(10,80-29,44) \\
g=8\end{array}$ & $\begin{array}{c}16,54^{3 A B} \\
(9,29-39,72) \\
n=8\end{array}$ & $\begin{array}{c}16,68^{2 A B} \\
(6,95-33,06) \\
n=8\end{array}$ & $\begin{array}{c}15,83^{A A B} \\
(9,71-33,53) \\
n=8 \\
\end{array}$ & $\begin{array}{c}16,26^{, A B} \\
(8,67-24,23) \\
2=8\end{array}$ & $\begin{array}{c}21,21 \text { aABC } \\
(4,02-31, \infty) \\
n=8\end{array}$ & $\begin{array}{c}16,69^{A A B} \\
(12,20-33,06) \\
n=8\end{array}$ \\
\hline $\begin{array}{l}\text { Ocitoc ina com } \\
\text { Propilenog licol }\end{array}$ & $\begin{array}{c}21,04^{-A B C} \\
(9,92-31,66) \\
n=7\end{array}$ & $\begin{array}{c}16,59^{2+18} \\
(8,88-35,50) \\
n=8\end{array}$ & $\begin{array}{c}22,14^{\text {ABC }} \\
(4,31-34,01) \\
n=8 \\
\end{array}$ & $\begin{array}{c}17,42^{-. A B C} \\
(11,95 \cdot 34,51) \\
n=8 \\
\end{array}$ & $\begin{array}{c}21,23^{2 A B C D} \\
(11,48 \cdot 40,28) \\
n=8\end{array}$ & $\begin{array}{c}\mathbf{2 0 , 5 5}{ }^{2+18 C} \\
(13,43 \cdot 26,54) \\
n=8 \\
\end{array}$ & $\begin{array}{c}19,40^{-A B C} \\
(12,68-41,41) \\
n=8 \\
\end{array}$ \\
\hline $\begin{array}{l}\text { Ocitoc ina com } \\
\text { Tween80 }\end{array}$ & $\begin{array}{c}15,85^{2 \lambda} \\
(5,08-23,13) \\
n=8\end{array}$ & $\begin{array}{c}16,29^{2 . \lambda \mathrm{B}} \\
(11,03-36,00) \\
n=8\end{array}$ & $\begin{array}{c}21,39^{2 A B C} \\
(10,13-25,30) \\
n=8\end{array}$ & $\begin{array}{c}19,57^{2 A B} \\
(12,20-26,54) \\
n=\$\end{array}$ & $\begin{array}{c}18,41^{=A B} \\
(7,32-35,50) \\
n=8\end{array}$ & $\begin{array}{c}18,33^{2 \lambda B} \\
(9,08-26,34) \\
n=8\end{array}$ & $\begin{array}{c}17,26^{2 A B} \\
(5,73-27,34) \\
n=8\end{array}$ \\
\hline
\end{tabular}

Notas:

$1-a, b, c, d$ nas linhas. Medianas com pelo menos uma letra minúscula em comum são equivalentes $(\mathrm{p}>0,05)$.

$2 \cdot A, B, C, D, E, F$ nas colunas. Medianas com pelo menos uma letra maiúscula em comum são equivalentes $(\mathrm{p}>0,05)$.

A concentração plasmática basal média de ocitocina (tempo zero) de todos os animais foi de $18,33 \pm 2,18$ $\mathrm{pg} / \mathrm{mL}$ e não diferiu entre eles $(\mathrm{p}>0,05)$. A concentração obtida no tempo zero nos animais que receberam ocitocina endovenosa foi menor que nos demais tempos $(3,6,9,12$ e $18 \mathrm{~min})$. Tabela 1 ( $<<0,05)$.

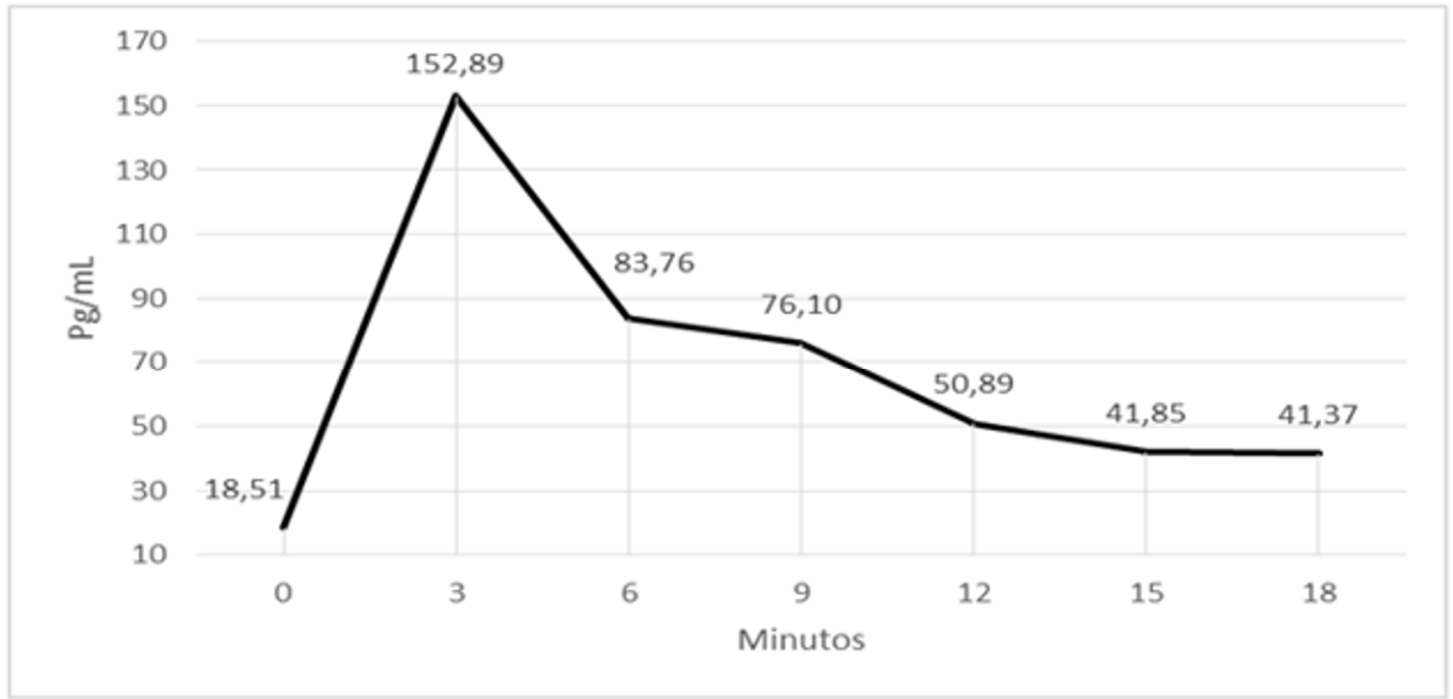

Gráfico 1. Concentração plasmática média de ocitocina após aplicadação de 10 UI pela via endovenosa. 
As elevadas concentrações médias de ocitocina plasmática obtidas com aplicação pela via endovenosa já eram previstas e pretendidas (Gráfico 1). Previstas porque a ocitocina foi aplicada em dose maior do que a necessária para a ejeção do leite. Além disso, foi aplicada e medida diretamente no sangue. Pretendida para que a sua biodisponibilidade, que por definição corresponde a $100 \%{ }^{(16)}$, servisse como parâmetro para o cálculo da biodisponibilidade da ocitocina associada aos fármacos aplicados pela via vaginal.

Foi observado que houve absorção de ocitocina quando a formulação de ocitocina em glicerina foi aplicada via vaginal, tendo sido verificada diferença entre os tempos 0 e 12 minutos; Tabela 1 $(\mathrm{p}<0,05)$. O Gráfico 2 demonstra a concentração plasmática média de ocitocina obtida com esse tratamento ao longo do tempo.

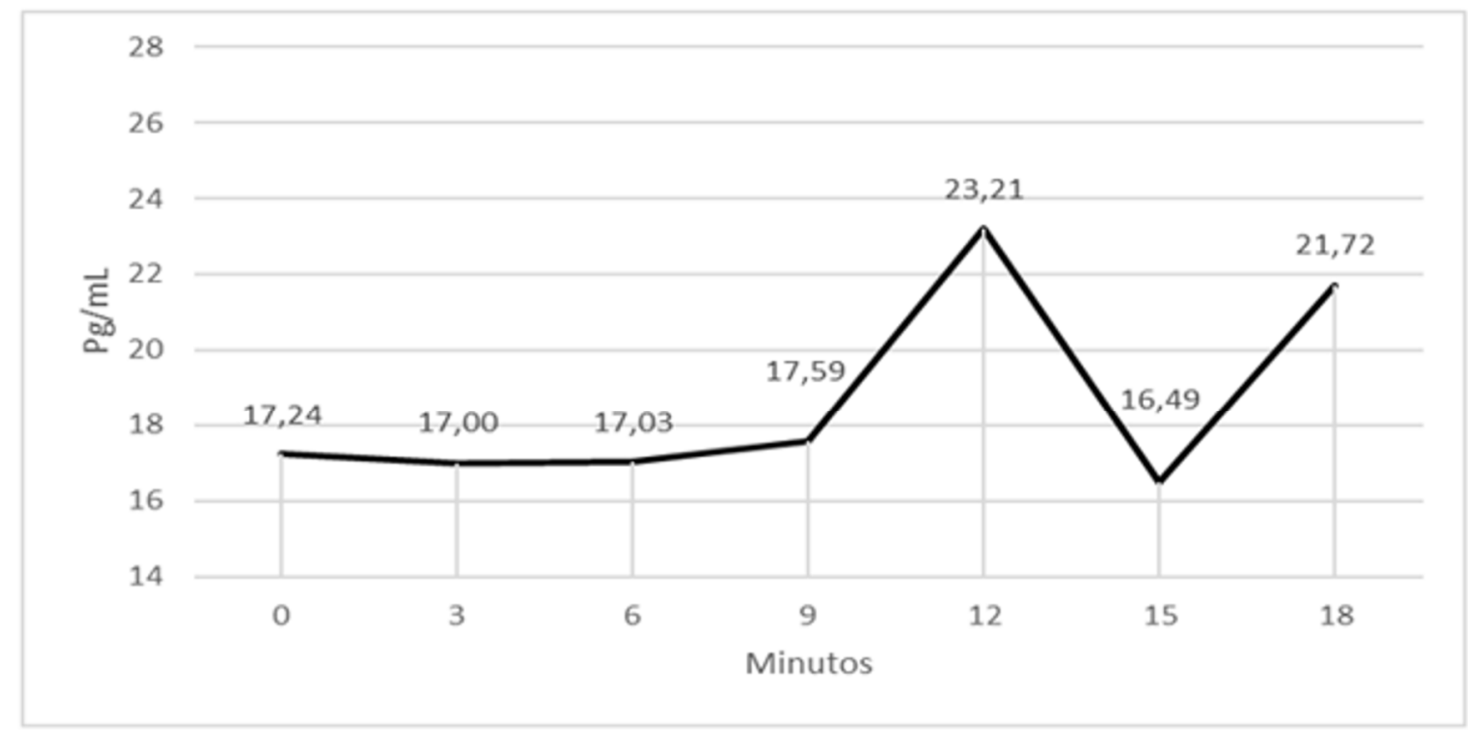

Gráfico 2. Concentração plasmática média de ocitocina ao longo do tempo obtida com aplicação vaginal de $2 \mathrm{~mL}$ (10 UI) da formulação de ocitocina em glicerina

A concentração plasmática basal média de ocitocina nos animais que receberam a formulação de ocitocina em glicerina foi de 17,24 $\pm 5,96 \mathrm{pg} / \mathrm{mL}$, alcançando a concentração média de 23,21 $\pm 6,74$ pg/mL aos 12 minutos após aplicação. Verificou-se, dessa forma, um acréscimo de 5,97 pg/mL na concentração média $(p<0,05)$. Schams et al. ${ }^{(17)}$ obtiveram máxima ejeção do leite com acréscimo de 3,02 a $5,03 \mathrm{pg} / \mathrm{mL}$ (valores originais em $\mathrm{pmol} / \mathrm{L}$ foram transformados para $\mathrm{pg} / \mathrm{mL}$ multiplicando por 1007,19 e dividindo por 1000).

A área sob a curva (ASC) endovenosa obtida pela aplicação de ocitocina endovenosa foi de 1.306,30 $\mathrm{pg} / \mathrm{mL}$ x minuto. A ASC mucosa obtida pela aplicação de ocitocina em glicerina na mucosa vaginal foi de $332,35 \mathrm{pg} / \mathrm{mL}$ x minuto. Assim, a biodisponibilidade (F) de ocitocina encontrada nessa formulação foi de $25,44 \%$.

Não houve diferença entre as concentrações de ocitocina ao longo do tempo para os demais tratamentos (Ocitocina em Água, Ocitocina em Álcool Polivinílico, Ocitocina em Carboxi Metil Celulose (CMC)' Ocitocina em Dimetilsulfóxido (DMSO), Ocitocina em Propilenoglicol, Ocitocina em Tween 80). 


\section{Discussão}

A glicerina foi associada à ocitocina na formulação sugerida pela empresa Fagron BR, em informe técnico de formulação de spray nasal ${ }^{(18)}$. Segundo o informe, com essa associação, a ocitocina é prontamente absorvida, entrando na circulação sistêmica. A glicerina é também um dos compostos utilizados como excipiente na formulação Syntocinon ${ }^{\circledR}$ spray nasal do Laboratório Novartis, vendida comercialmente para humanos ${ }^{(19)}$.

As análises estatísticas demonstraram também que as concentrações plasmáticas de ocitocina aos 12 minutos não diferiram entre as formulações ocitocina em glicerina absorvida pela mucosa vaginal e a ocitocina endovenosa, que não passou pelo processo de absorção.

A concentração plasmática basal média de ocitocina encontrada $(18,33 \mathrm{pg} / \mathrm{mL})$ foi maior que o encontrado por Schams et al. ${ }^{(17)}, 1,51 \mathrm{pg} / \mathrm{mL}$ de plasma (valores originais em $\mathrm{pmol} / \mathrm{L}$ foram transformados para $\mathrm{pg} / \mathrm{mL}$ multiplicando por 1007,19 e dividindo por 1000) em vacas da raça Pardo Suíço; por Bruckmaier et al., ${ }^{(9)}$ 1,5 pg/mL (valor original em $\mathrm{ng} / \mathrm{L}$ que equivale a $\mathrm{pg} / \mathrm{mL}$ ) em vacas Simental x Holandês Vermelho e Pardo Suíço, e por Bruckmaier et al. ${ }^{(20)}$, com vacas Simental x Holandês Vermelho e Pardo Suíço, que encontraram concentração basal média de 6 e $7 \mathrm{pg} / \mathrm{ml}^{5}$. No entanto, a concentração basal foi menor que as encontradas por Porcionato et al. ${ }^{(21)} \mathrm{em}$ vacas da raça Holandês, média de 20 pg/mL, e em vacas mestiças Holandês x Zebu, média de $35 \mathrm{pg} / \mathrm{mL}$.

A concentração basal de ocitocina plasmática depende da liberação endógena pela neurohipófise e/ou da liberação de ocitocina lútea. Entretanto, outros fatores parecem interferir nessa liberação. Em experimento com primatas (Macaca mulatta), Michopoulos et al. ${ }^{(22)}$ verificaram diferença na concentração basal de ocitocina dos animais em função da dominância. Fêmeas dominantes têm concentração maior que subordinadas. Uvnäs-Moberg et. al. ${ }^{(23)}$ relataram diferenças na concentração basal de ocitocina em função do comportamento sexual em humanos (monogamia e satisfação sexual). Parceiros satisfeitos têm concentração mais elevada. Marnet et al. ${ }^{(24)}$, em trabalho realizado na França, observaram diferença na concentração basal de ocitocina conforme a estação do ano, quando a concentração de ocitocina em ovelhas ordenhadas foi maior no outono que na primavera (27,5 pg/mL e $12 \mathrm{pg} / \mathrm{mL}$, respectivamente).

É provável que outros fatores capazes de interferir na concentração plasmática de ocitocina ainda não tenham sido identificados ou estudados. Por exemplo, com referência a raça e idade. Quanto à raça, Porcionato et al. ${ }^{(21)}$ encontraram valor de ocitocina basal maior em vacas mestiças Holandês x Zebu do que em vacas Holandês $(\mathrm{p}<0,05)$. Quanto à idade, nos trabalhos consultados sobre concentração plasmática de ocitocina, todos utilizaram animais adultos, nenhum com novilhas como foi feito nesse experimento.

\section{Conclusões}

Houve absorção de ocitocina pela via mucosa vaginal da formulação ocitocina em glicerina. O pico de concentração plasmática de ocitocina ocorreu aos 12 minutos após a aplicação.

O aumento da concentração plasmática de ocitocina atingido com a aplicação da formulação ocitocina 
com glicerina, de acordo com a literatura, seria suficiente para conseguir a ejeção do leite em vacas.

\section{Agradecimentos}

Os autores agradecem à FAPEMIG, pela aprovação e pela liberação de recursos que viabilizaram este experimento, por meio do projeto APQ-01987-13.

\section{Referências}

1. Molina PE. Fisiologia endócrina. $4^{\mathrm{a}}$ ed. São Paulo: AMGH; 2014.

2. Hafez ESE, Jainudeen MR, Rosnina Y. Hormônios, Fatores de crescimento e reprodução. In: Hafez ESE, Hafez B, editores. Reprodução Animal. $7^{\mathrm{a}}$ ed. São Paulo: Manole Ltda; 2004.p.33-53.

3. Nogueira GP, Farmacologia do Eixo Hipotálamo-Hipófise. In: Spinosa HS, Górniak SL, Bernardi MM. Farmacologia aplicada a Medicina Veterinária. $5^{a}$ ed. Rio de Janeiro: Guanabara Koogan; 2011. P.345-362.

4. Bruckmaier RM; Ritter C, Schams D, Blum JW. Machine milking of dairy goats during lactation: udder anatomy, milking characteristics, and blood concentrations of oxytocin and prolactin. J Dairy Res. 1994 Nov; 61(4): 457-66. Disponível em: https://doi.org/10.1017/S0022029900028387.

5. Santos MV, Fonseca LFL. Estratégias para controle de mastite e melhoria da qualidade do leite. São Paulo: Manole Ltda; 2007.

6. Madalena FE, Abreu CP, Sampaio IBM, Ferreira Sobrinho F. Práticas de cruzamentos em fazendas leiteiras afiliadas à cooperativa central de produtores rurais de Minas Gerais. R. Bras. Zootec. 1997 Set/Out; 26(5): 924-34. Disponível em: http://www.fernandomadalena.com/site arquivos/041.pdf

7. Bruckmaier RM, Schams D, Blum JW. Continuously elevated concentrations of oxytocin during milking are necessary for complete milk removal in dairy cows. J Dairy Res. 1994 Ago; 61(3): 323-34, Disponível em: https://doi.org/10.1017/S0022029900030740

8. Bruckmaier RM, Blum JW. Oxytocin release and milk removal in ruminants. J. Dairy Sci. 1998 Abr; 81(4): 939-49. Disponível em: http://dx.doi.org/10.3168/jds.S0022-0302(98)75654-1

9. Bruckmaier RM, Schams D, Blum JW. Milk removal in familiar and unfamiliar surroundings: concentration of oxytocin, prolactin, cortisol, and b-endorphin. J Dairy Res. 1993 Nov; 60(4): 449-56. Disponível em: DOI: https://doi.org/10.1017/S0022029900027813

10. Bruckmaier RM, Schams D, Blum JW. Aetiology of disturbed milk ejection in parturient primiparous cows. J Dairy Res. 1992 Nov; 59(4): 479-89. Disponível em: https://doi.org/10.1017/S002202990002714X

11. Alvarez FJ, Saucedo G, Arriaga A, Preston TR. Effect on milk production and calf performance of milking cross bred european/zebu cattle in the abstence or presence of the calf, and of rearing their calves artificially. Trop Anim Prod. 1980; 5(1): 25-37. Disponível em: http://www.fao.org/livestock/AGAP/frg/TAP51/5 1 5.PDF

12. Professores da Escola investigam surto de Trypanossomose bovina em Minas Gerais (Internet). Belo Horizonte: Escola de Veterinária da Universidade Federal de Minas Gerais; Em 13 de Agosto de 2014. Acessado em 01.08.2016. Notícias (Aprox 2p). em:http://www.vet.ufmg.br/noticias/exibir/1943/professores da escola investigam surto de trypanossomo se bovina em mi\#.V9CL4PkrLIU

13. Abrão DC, Carvalho AÚ, Facury Filho EJ, Saturnino HM, Ribeiro MFB. Impacto econômico causado por 
trypanosoma vivax em rebanho bovino leiteiro no estado de Minas Gerais. Ciênc. Anim. Bras. 2009 Out, 1: 672-76. Disponível em: https://www.revistas.ufg.br/vet/article/view/7882/5716

14. Choudhury A, Das S, Kar M. A review on novelty and potentiality of vaginal drug delivery. Int J Pharm Tech Res. 2011 Abr/Jun; 3(2); 1033-44. Disponível em: https:/www.researchgate.net/publication/264871067

15. Patel A, Patel J. Vagina as an application site for drug delivery. IJNDD. 2012 Jan/Mar; 4(1): 17-23. Disponível em: http://www.ijndd.net/jan-mar2012/IJNDD\%203_4_,\%20Jan-Mar,\%202012,\%201723 Review\%20article Anita\%20Patel.pdf

16. Brown AS. Farmacocinética: Distribuição e destino das drogas no organismo. In Adams HR, editor. Farmacologia e terapêutica em veterinária. Rio de Janeiro: Guanabara Koogan; 2003. p.11-47.

17. Schams D, Mayer H, Prokopp A, Worstorff H. Oxytocin secretion during milking in dairy cows with regard to the variation and importance of a threshold level for milk removal. J. of Endocrinology. 1984; 102: 337-43. Disponível em: http://joe.endocrinology-journals.org/content/102/3/337

18. Oxitocina (Internet). São Paulo: Fagron BR; 2013. Acessado em 02.01.2014. Informe Técnico (Aprox 5p). Disponível em: http://www.farmabin.com.br/files/OXITOCINA.pdf

19. Syntocinon ${ }^{\circledR}$ ocitocina (Internet). São Paulo: Novartis; 2015. Acessado em 15.09.2015. Bula. (Aprox 4p). Disponível em: https://portal.novartis.com.br/UPLOAD/ImgConteudos/2762.pdf

20. Bruckmaier RM, Wellnitz O, Blum JW. Inhibition of milk ejection in cows by oxytocin receptor blockade, $\alpha$-adrenergic receptor stimulation and in unfamiliar surroundings. J Dairy Res. 1997 Ago; 64(3); 315-25. Disponível em: https://www.cambridge.org/core/journals/journal-of-dairy-research/article/inhibition-of-milkejection-in-cows-by-oxytocin-receptor-blockade-adrenergic-receptor-stimulation-and-in-unfamiliarsurroundings/EE745E67333266B012616EB0D52C673E

21. Porcionato MAF, Negrão JÁ, Lima MLP. Produção de leite, leite residual e concentração hormonal de vacas Gir x Holandesa e Holandesa em ordenha mecânica exclusiva. Arq. Bras. Med. Vet. Zootec. 2005; 57(6): 820-4. Disponível em: http://dx.doi.org/10.1590/S0102-09352005000600018

22. Michopoulos V, Checchi M. Sharpe D, Wilson M.E. Estradiol effects on behavior and serum oxytocin are modified by social status and polymorphisms in the serotonin transporter gene in female rhesus monkeys. Horm Behav. 2011 Abr; 59(4): 528-35. Disponível em: http://doi.org/10.1016/j.yhbeh.2011.02.002

23. Uvnäs-Moberg K, Johansson B, Lupoli B, Svennersten-Sjaunja K. Oxytocin facilitates behavioral, metabolic and physiological adaptations during lactation. Appl Anim Behav Sci. 2001 Mai; 72(3): 225-34. Disponível em: http://dx.doi.org/10.1016/S0168-1591(01)00112-5

24. Marnet PG, Negrão JA, Labussière J. Oxytocin release and milk ejection parameters during milking of dairy ewes in and out of natural season of lactation. Small Rumin Res. 1998 Mai; 28(2): 183-91. Disponível em: http://doi.org/10.1016/S0921-4488(97)00075-8 